\title{
Crossed unfused renal ectopia
}

\author{
Srikanth Prasad, ${ }^{1}$ Joseph Thomas ${ }^{2}$
}

1 Department of Internal Medicine, Kasturba Medical College, Manipal, Karnataka, India

${ }^{2}$ Department of Medical Oncology, Kasturba Hospital Manipal, Karnataka, India

\section{Correspondence to}

Dr Srikanth Prasad,

srikanthprasadrao@yahoo.com srikanthprasadrao@gmail.com
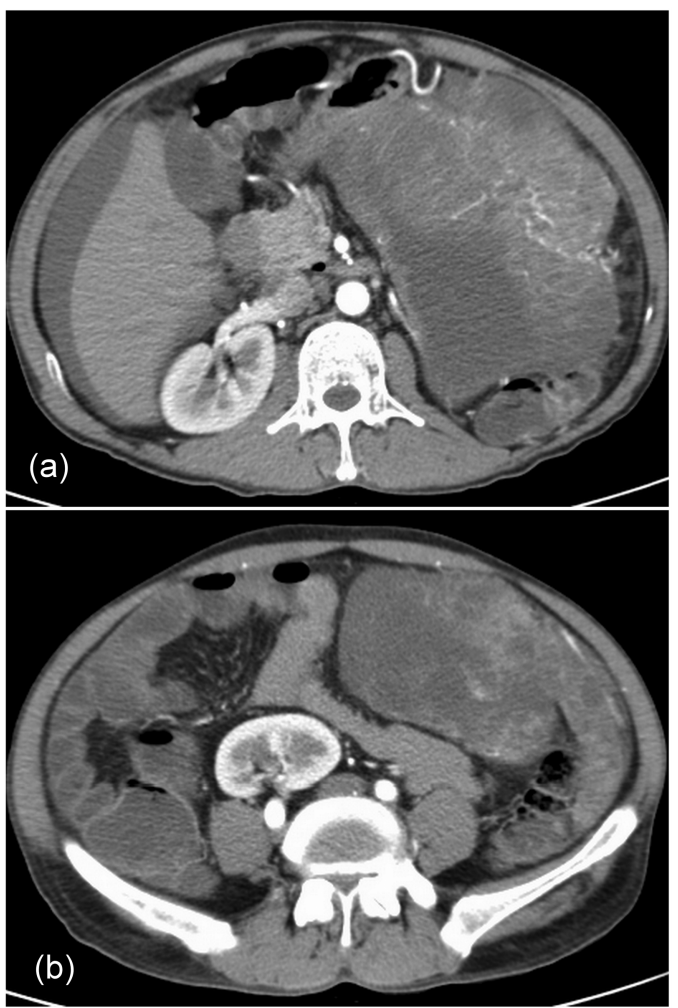

Figure 1 Axial section of contrast enhanced CT of the abdomen showing the right kidney in its normal position (A) and an ectopic left kidney situated in the right iliac fossa with the hilum facing posteriorly (B).
$25.7 \times 16.2 \times 12.6 \mathrm{~cm}$ arising from the greater curvature of the body of the stomach. The left kidney was ectopically located and seen in the right iliac fossa with the hilum facing posteriorly. The right ureter had a normal course and the left ureter crossed the midline and entered into the urinary bladder at the usual position (figures 1-3). A biopsy was taken from the mass which on histopathological examination revealed a gastrointestinal stromal tumour (GIST).

Crossed renal ectopia is a rare entity. It has been classified into 4 groups: (1) crossed fused renal ectopia, (2) crossed unfused renal ectopia, (3) bilaterally crossed kidneys and (4) solitary crossed kidney. ${ }^{1}$ Of these, the fused variety is the most common, followed by the unfused variety. The other two are extremely rare. Our patient had crossed unfused renal ectopia. The incidence of the unfused variety has been reported to be 1 in 75000 autopsies. $^{2}$ It is generally detected incidentally when the patient is being evaluated for other conditions. It may be associated with urinary abnormalities like urinary tract infection, renal calculi and ureteropelvic junction obstruction principally due to mechanical reasons. It may also be associated with skeletal, gastrointestinal and cardiopulmonary anomalies. ${ }^{1}$ In our patient, it was associated with GIST. It is most often asymptomatic and requires no specific treatment unless there are complications.

\section{Learning points}

- Crossed unfused ectopic kidney is a very rare condition

- CT scan is the diagnostic modality of imaging

- It is seldom symptomatic, requiring intervention.
To cite: Prasad $S$ Thomas J. BMJ Case Rep Published online: [please include Day Month Year] doi:10.1136/bcr-2013202960
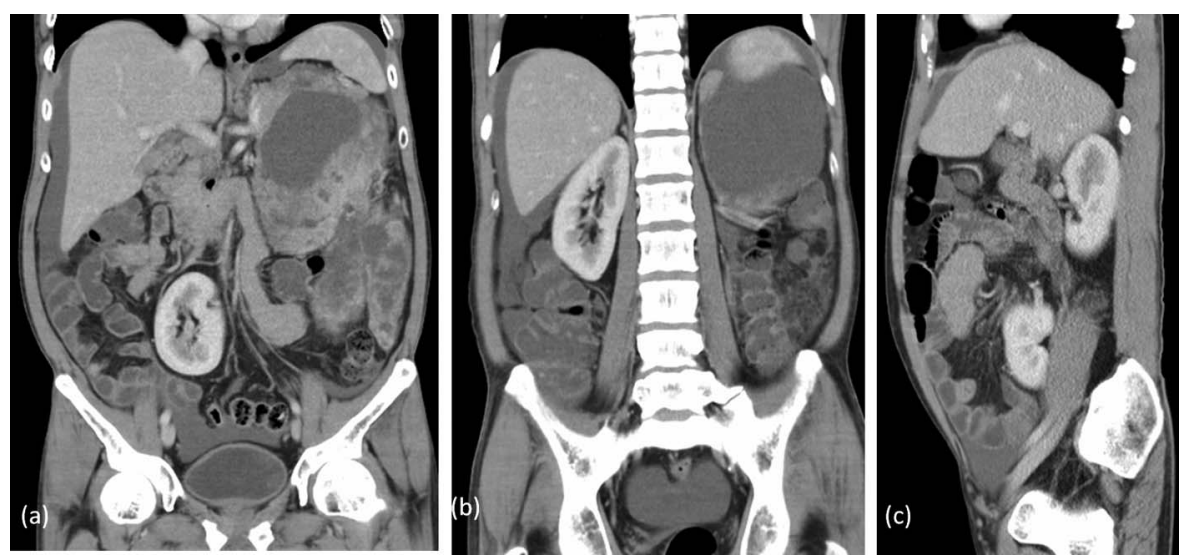

Figure 2 Coronal and sagittal sections of contrast enhanced CT of the abdomen showing an ectopic left kidney. 


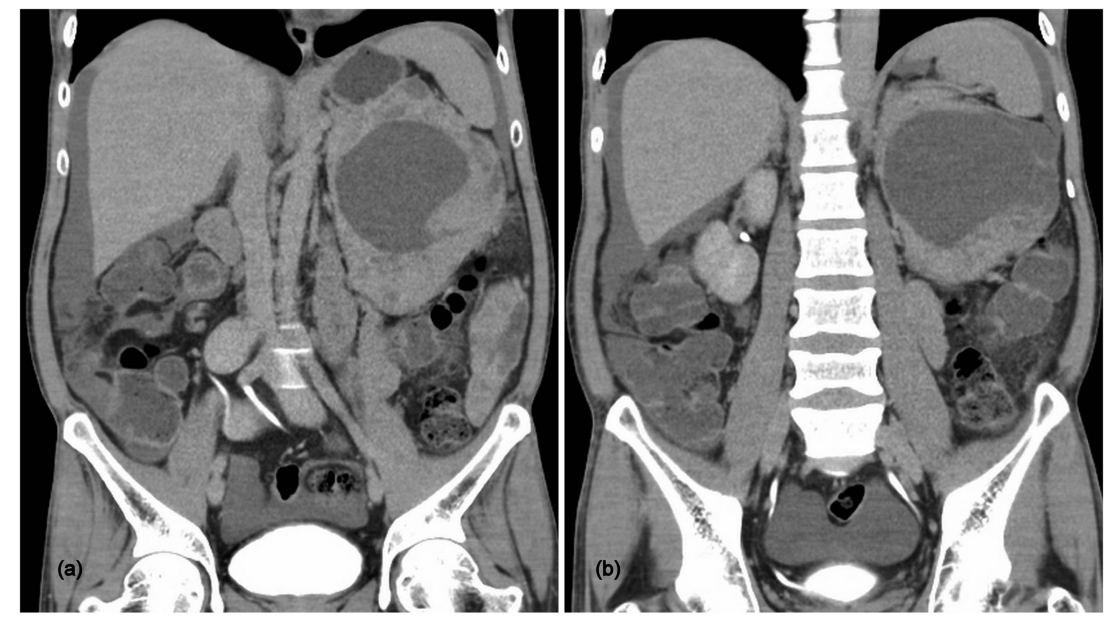

Figure 3 Coronal sections of contrast enhanced CT of the abdomen showing the normal course of the right ureter (A). The left ureter is seen to cross the midline and enter into the urinary bladder at the normal position (B).

Contributors SP was involved in the conception, design, acquisition of the images and drafting of the manuscript. JT was involved in revising it critically for important intellectual content and final approval of the version published.

\section{Competing interests None.}

Patient consent Obtained.

Provenance and peer review Not commissioned; externally peer reviewed.

\section{REFERENCES}

1 Mansberg VJ, Rossleigh MA, Farnsworth RH, et al. Unfused crossed renal ectopia with ectopic left ureter inserting into a prostatic utricle diverticulum. AJR Am J Roentgenol 1999;172:455-6.

2 Felzenberg J, Nasrallah PF. Crossed renal ectopia without fusion associated with hydronephrosis in an infant. Urology 1991; 38:450-2.

Copyright 2014 BMJ Publishing Group. All rights reserved. For permission to reuse any of this content visit http://group.bmj.com/group/rights-licensing/permissions.

BMJ Case Report Fellows may re-use this article for personal use and teaching without any further permission.

Become a Fellow of BMJ Case Reports today and you can:

- Submit as many cases as you like

- Enjoy fast sympathetic peer review and rapid publication of accepted articles

- Access all the published articles

- Re-use any of the published material for personal use and teaching without further permission

For information on Institutional Fellowships contact consortiasales@bmjgroup.com

Visit casereports.bmj.com for more articles like this and to become a Fellow 